\title{
Synthesis and Purple-Blue Emission of Antimony Trioxide Single-Crystalline Nanobelts with Elliptical Cross Section
}

\author{
Zhengtao Deng ${ }^{1,2,3}$, Dong Chen ${ }^{1}$, Fangqiong Tang ${ }^{1}(\varangle)$, Jun Ren ${ }^{1}$, and Anthony J. Muscat ${ }^{2}$ \\ ${ }^{1}$ Laboratory of Controllable Preparation and Application of Nanomaterials, Technical Institute of Physics and Chemistry, Chinese \\ Academy of Sciences, Beijing 100080, China \\ ${ }^{2}$ Department of Chemical and Environmental Engineering, The University of Arizona, Tucson, Arizona 85721, USA \\ ${ }^{3}$ College of Optical Science, The University of Arizona, Tucson, Arizona 85721, USA \\ Received: 13 October 2008 / Revised: 15 December 2008 / Accepted: 15 December 2008 \\ (C)Tsinghua University Press and Springer-Verlag 2009. This article is published with open access at Springerlink.com
}

\begin{abstract}
Single-crystalline orthorhombic antimony trioxide $\left(\mathrm{Sb}_{2} \mathrm{O}_{3}\right)$ nanobelts with unique elliptical cross sections and purple-blue photoluminescence have been synthesized. The uniform $\mathrm{Sb}_{2} \mathrm{O}_{3}$ nanobelts are $400-600 \mathrm{~nm}$ in width, 20-40 nm in thickness at the center and gradually become thinner to form sharp edges sub-5 $\mathrm{nm}$ in size, tens of micrometers in length, and with [001] as the preferential growth direction. Self-assembly of tens of nanobelts into three-dimensional (3-D) flower-like nanostructures has been observed. Analysis was performed by X-ray diffraction, energy-dispersive X-ray spectroscopy, X-ray photoelectron spectroscopy, scanning electron microscopy, high-resolution transmission electron microscopy, selected area electron diffraction, Raman spectroscopy, Fourier transform infrared spectroscopy, and photoluminescence spectroscopy. The $\mathrm{Sb}_{2} \mathrm{O}_{3}$ nanobelts display intense purple-blue photoluminescence centred at $425 \mathrm{~nm}(\sim 2.92 \mathrm{eV})$. The successful synthesis of nanobelts with elliptical cross sections may cast new light on the investigation of the property differences between nanobelts with rectangular cross sections and those with other cross section geometries. The $\mathrm{Sb}_{2} \mathrm{O}_{3}$ nanobelts can be used as effective purple-blue light emitters and may also be valuable for future nanodevice design.
\end{abstract}

\section{KEYWORDS}

Antimony trioxide, nanobelts, elliptical cross section, purple-blue, photoluminescence

\section{Introduction}

Since the discovery of nanobelts of semiconducting oxides in 2001 [1], nanobelts have attracted considerable attention due to their dimensionally confined and structurally well-defined physical and chemical properties, and their potential applications in nanodevices such as field effect transistors, ultrasensitive gas sensors, resonators, and cantilevers [2-8]. Generally, nanobelts have a rectangular cross section and well-defined faceted surfaces [4]. $\mathrm{ZnO}$ nanobelts with rectangular cross sections have been used as effective Fabry-Perot microcavities for lasing [9]. Recent research suggests that, in addition to size and dimension, the cross section also has a shape effect on the properties of nanomaterials [10].

Address correspondence to: tangfq@mail.ipc.ac.cn 
According to classical waveguide theory, waveguides with different cross sections will exhibit different transverse optical modes [4]. Therefore, the synthesis of metal oxide semiconductor nanobelts with cross sections other than rectangular is an urgent requirement for both fundamental research and technological application.

Recently, integration of one-dimensional (1-D) nanostructures - such as nanowires and nanobelts -into two- and three-dimensional (2-D and 3-D) hierarchical nanostructures or complex functional architectures, which are essential for the success of bottom-up approaches toward advanced materials and devices, has been one of the challenging issues faced by chemists [11-16]. To date, simple 1-D $\mathrm{Sb}_{2} \mathrm{O}_{3}$ nanostructures such as nanorods, nanowires, nanotubes, and nanoribbons have been synthesized via a variety of processes [17-24]. For example, $\mathrm{O}^{\prime}$ Brien et al. [22] reported that refluxing antimony acetate with octylamine afforded $\mathrm{Sb}_{2} \mathrm{O}_{3}$ nanostructures. More recently, Sendor et al. [23] synthesized $\mathrm{Sb}_{2} \mathrm{O}_{3}$ nanoribbons with lengths up to $15 \mu \mathrm{m}$ and diameters ranging between 8 and $50 \mathrm{~nm}$ by a solid-to-nanostructure transformation route. However, $\mathrm{Sb}_{2} \mathrm{O}_{3}$ 3-D nanostructures built up from simple 1-D nanowires or nanobelts have not been obtained so far.

An important member of the class of functional metal oxides, $\mathrm{Sb}_{2} \mathrm{O}_{3}$ has been widely used as a fire retardant, a filler, a catalyst, and in $\mathrm{pH}$ electrodes [25 -28]. Similar to other well-studied functional metal oxides, $\mathrm{Sb}_{2} \mathrm{O}_{3}$ is also expected to be an interesting semiconducting material exhibiting unique optical, electronic, and optoelectronic properties. Recently, our group has reported the room temperature ultraviolet band-edge photoluminescence centered at $374 \mathrm{~nm}$ for $\mathrm{Sb}_{2} \mathrm{O}_{3}$ single crystalline nanowires [24]. More studies are still needed to explore the optical and electronic properties of various $\mathrm{Sb}_{2} \mathrm{O}_{3}$ nanostructures in order to fully understand the nature of $\mathrm{Sb}_{2} \mathrm{O}_{3}$.

Herein, the synthesis of single-crystalline $\mathrm{Sb}_{2} \mathrm{O}_{3}$ nanobelts with unique elliptical cross sections and their self-assembly into 3-D flowerlike nanostructures is described. The advantages of the present work are the following: (1) Uniform well-crystallized single-crystalline $\mathrm{Sb}_{2} \mathrm{O}_{3}$ nanobelts with unique elliptical cross sections have been synthesized; to our knowledge, nanobelts with elliptical cross sections have not been reported previously. (2) $\mathrm{Sb}_{2} \mathrm{O}_{3}$ 3-D nanostructures built up from simple 1-D nanobelts were achieved; this is the first synthesis of 3-D nanostructures of $\mathrm{Sb}_{2} \mathrm{O}_{3}$. (3) The new $\mathrm{Sb}_{2} \mathrm{O}_{3}$ nanobelts exhibited intense purple-blue photoluminescence centered at $425 \mathrm{~nm}$.

\section{Experimental}

Our group has developed a strategy for the synthesis of various oxide and oxyhalide nanostructures such as $\mathrm{Sb}_{2} \mathrm{O}_{3}, \mathrm{SnO}_{2}, \mathrm{BiOCl}$, and $\mathrm{BiOBr}$, by a facile route involving direct air oxidation of bulk metal particles in a mixed solution of ethylenediamine (EA) and deionized water (DIW) [29-32]. The synthesis processes for $\mathrm{Sb}_{2} \mathrm{O}_{3}$ nanobelts with elliptical cross sections and their flower-like nanostructures followed this strategy but with alteration of the experimental parameters. In a typical experiment, $120 \mathrm{mg} \mathrm{Sb}$ powder (<200 mesh, 99.5\%), $400 \mathrm{mg}$ polyvinylpyrrolidone (PVP, MW 30000) and $15 \mathrm{mmol}$ EA, were added to $74 \mathrm{~mL}$ DIW. The mixed solution was first stirred at $60{ }^{\circ} \mathrm{C}$ for $1 \mathrm{~h}$ and then kept at room temperature without disturbance for about $72 \mathrm{~h}$. After the reaction, the resulting white solid product was filtered and washed with DIW and ethanol to remove residual ions in the product. The final product was then dried in air at $60{ }^{\circ} \mathrm{C}$ for $4 \mathrm{~h}$ before characterization.

X-ray powder diffraction (XRD) measurements employed a Rigaku D/max yA X-ray diffractometer equipped with graphite monochromatized $\mathrm{Cu} \mathrm{K \alpha}$ radiation ( $\lambda=1.5418 \AA$ ) with a scanning rate of $0.02\left(^{\circ}\right) / \mathrm{s}$. Scanning electron microscopy (SEM) and energy-dispersive $\mathrm{X}$-ray spectroscopic (EDS) measurement were performed using a Hitachi S-4300 scanning electron field emission microscope operating at $15 \mathrm{kV}$. X-ray photoelectron spectroscopy (XPS) was performed using an achromatic Al Ka source $(1486.6 \mathrm{eV})$ and a double pass cylindrical mirror analyzer (Physical Electronics 549). Survey and high-resolution spectra were recorded at pass energies of 200 and $50 \mathrm{eV}$, respectively. Peak fitting was performed using multi-peak fitting packages 
included with Igor Pro (WaveMetrics, Inc., v.6). The atomic ratios were obtained from ratios of XPS peak areas in the high-resolution spectra corrected by sensitivity factors from the Ref. [33]. Transmission electron microscopy (TEM), highresolution TEM (HRTEM), and selected area electron diffraction (SAED) patterns were performed on a JEOL JEM-2010 electron microscope operating at 200 kV. Micro-Raman experiments were conducted in a Raman scattering spectrometer (LabRAM HR, HORIBA Jovin Yvon), with the $514.5 \mathrm{~nm}$ line of an $\mathrm{Ar}^{+}$laser as the excitation source. Fourier transform infrared (FT-IR) spectra were recorded with a Varian 3100 FT-IR spectrometer at room temperature. Photoluminescence (PL) spectra were measured with a Hitachi F4500 fluorescence spectrophotometer at room temperature.

\section{Results and discussion}

Figure 1(a) shows a typical XRD pattern of the assynthesized product. All the diffraction peaks of the sample can be readily indexed as the orthorhombic phase of $\mathrm{Sb}_{2} \mathrm{O}_{3}$ (cell constants $a=4.911 \AA, b=12.464$ $\AA$, $c=5.412 \AA$; JCPDS Card No. 11-0689). No peaks from metallic $\mathrm{Sb}$ or any other phases are detected. In addition, the intense and sharp diffraction peaks suggest the as-synthesized product is well crystallized. Furthermore, the (110) and the (200) peak intensities are significantly enhanced, and the (121) and the (131) peak intensities are considerably decreased relative to bulk orthorhombic phase valentinite, indicating the preferred crystallographic orientation of the product. To determine the composition of the product, EDS was performed on an individual nanobelt, as shown in Fig. 1(b). Only $\mathrm{Sb}$ and $\mathrm{O}$ peaks are observed in the spectrum (the Si signal arises from the silicon substrate), suggesting that the product is composed of $\mathrm{Sb}$ and O. Quantitative EDS analysis shows that the atom ratio $\mathrm{Sb}: \mathrm{O}$ is $39: 61$, close to $2: 3$, indicating the composition of the as-synthesized product is $\mathrm{Sb}_{2} \mathrm{O}_{3}$.

The survey XPS spectrum shown in Fig. 2(a) indicates that the nanobelts contain $\mathrm{Sb}, \mathrm{O}$, and $\mathrm{C}$. Surface charging was corrected by referencing the spectra to the $\mathrm{C}-\mathrm{C}$ state of the $\mathrm{C} 1$ s peak at a binding

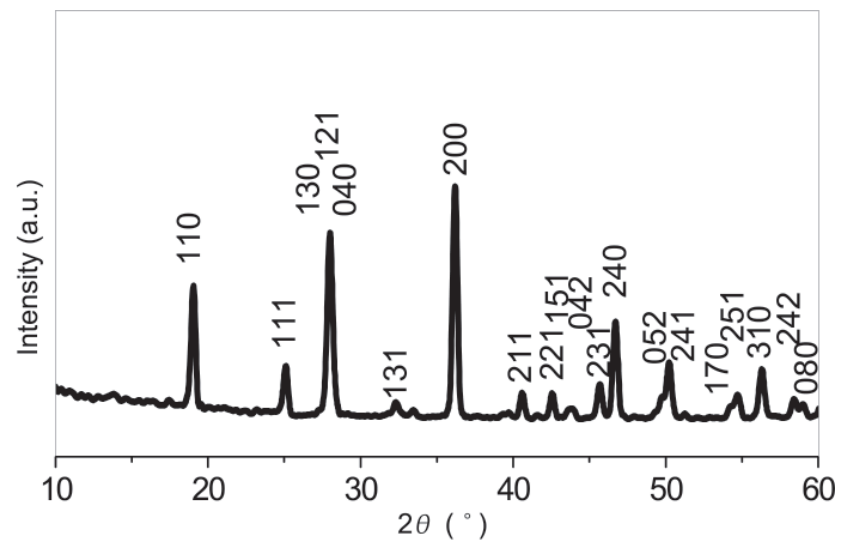

(a)

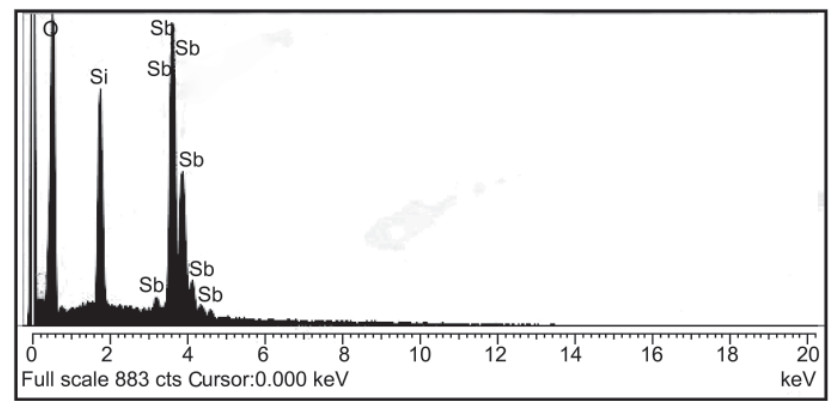

(b)

Figure 1 (a) XRD and (b) EDS patterns of $\mathrm{Sb}_{2} \mathrm{O}_{3}$ nanbelts

energy of $284.5 \mathrm{eV}$. Since the $\mathrm{Sb} 3 \mathrm{~d}_{5 / 2}$ region overlaps with the $\mathrm{O} 1 \mathrm{~s}$ region, peak fitting was performed for the high-resolution XPS spectra as shown in Fig. 2(b). The Sb 3d spectrum exhibited two peaks: One at $539.2 \mathrm{eV}$, which was assigned to $\mathrm{Sb} 3 \mathrm{~d}_{3 / 2}$, and one at $529.9 \mathrm{eV}$, which was assigned to $\mathrm{Sb} 3 \mathrm{~d}_{5 / 2}$. The two peaks are due to spin-orbit coupling of the $3 \mathrm{~d}$ state with a spin-orbit separation of $9.3 \mathrm{eV}$ and a spinorbit branching ratio of 1.67 , which agrees well with that reported previously for $\mathrm{Sb}_{2} \mathrm{O}_{3}[34,35]$. The $\mathrm{Sb}$ $3 \mathrm{~d}_{3 / 2}$ region showed a single peak at a binding energy of $539.2 \mathrm{eV}$, indicating that the sample was composed of only the $\mathrm{Sb}$ (III) state, with no significant amounts of $\mathrm{Sb}(0)$, which is expected at $537.6 \mathrm{eV}$, nor $\mathrm{Sb}(\mathrm{V})$, which occurs at $540.3 \mathrm{eV}$. The $\mathrm{O} 1 \mathrm{~s}$ region shown in Fig. 2(b) contained a single symmetric peak at 528.5 $\mathrm{eV}$ assigned to $\mathrm{O}$ in $\mathrm{Sb}_{2} \mathrm{O}_{3}$. The shift to lower binding energy compared to other oxide species shows that the $\mathrm{Sb}-\mathrm{O}$ bond is primarily ionic. The total $\mathrm{Sb}: \mathrm{O}$ ratio computed on the basis of peak areas and sensitivity factors is about 0.63 ; this value is also consistent with the composition $\mathrm{Sb}_{2} \mathrm{O}_{3}$.

SEM images shown in Figs. 3(a)-3(d) and the 


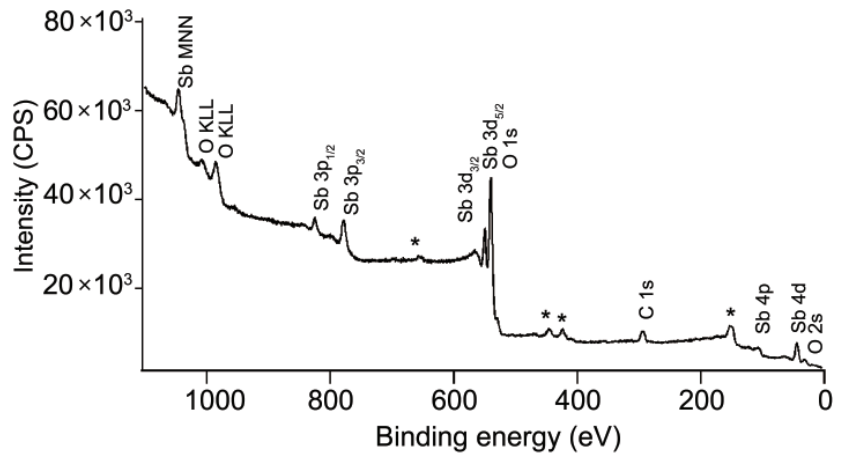

(a)

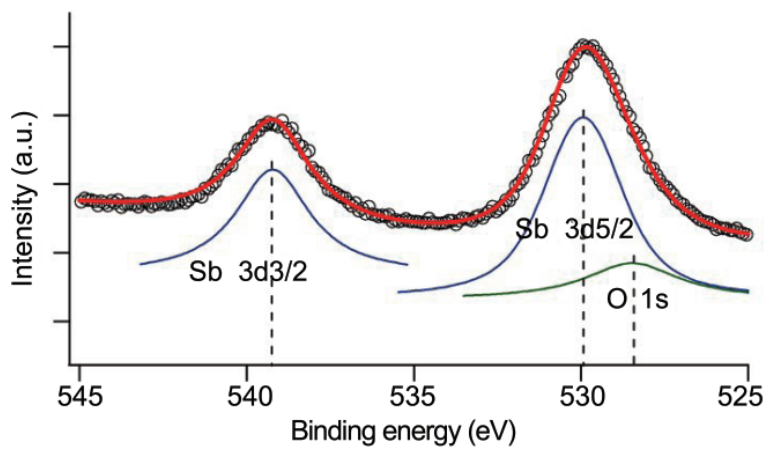

(b)

Figure 2 (a) Survey $X$-ray photoelectron spectrum of $\mathrm{Sb}_{2} \mathrm{O}_{3}$ nanobelts; (b) high-resolution X-ray photoelectron spectra of $\mathrm{Sb}_{2} \mathrm{O}_{3}$ nanobelts in the $\mathrm{Sb}$ and $\mathrm{O}$ regions. Note the small peaks marked by * come from the lead from the substrate

Electronic Supplementary Material (ESM) reveal that the as-synthesized product is composed of a large quantity of individual nanobelts together with 3-D flower-like nanostructures made up of dense assemblies of numerous individual nanobelts. Highmagnification SEM images (see Figs. 3(e), 3(f), and the ESM) show that the $\mathrm{Sb}_{2} \mathrm{O}_{3}$ nanobelts are very highly uniform. Most of the individual nanobelts were 400-600 $\mathrm{nm}$ in width and tens of micrometers in length. Closer inspection revealed that the 1-D nanobelts appeared to have an ideal belt-like morphology with elliptical cross sections, i.e., 20 $-40 \mathrm{~nm}$ in thickness at the center and gradually becoming thinner to form sharp edges sub- $5 \mathrm{~nm}$ in size (see Figs. 3(g), 3(h), and the ESM). Eklund et al. [10] pointed out that the cross section also has a shape effect on the properties of nanomaterials in addition to their size and dimensions. In addition, waveguides of different cross sections will exhibit different transverse optical modes [4]. Therefore, the unique structure of the nanobelts with elliptical cross

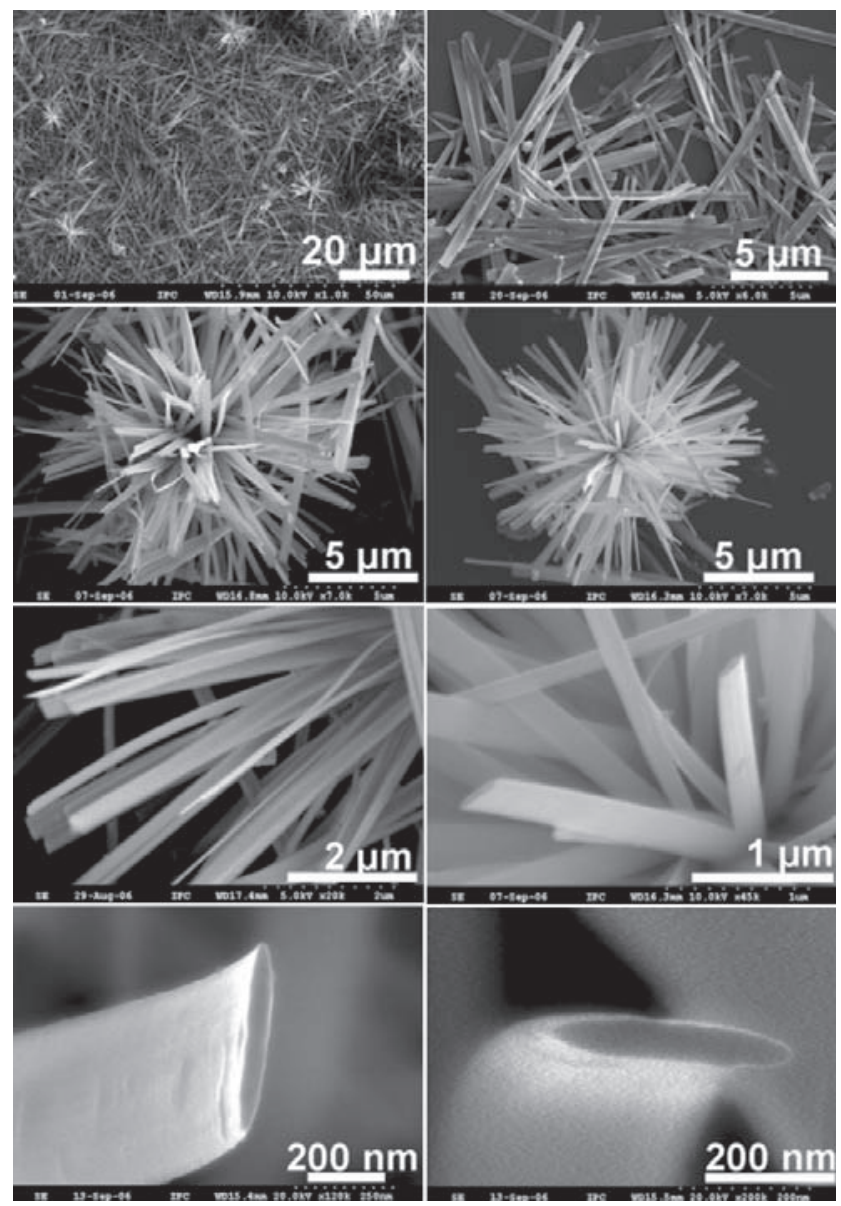

Figure 3 (a) Low-magnification SEM image of the $\mathrm{Sb}_{2} \mathrm{O}_{3}$ product; (b) SEM image of the individual nanobelts; (c), (d) SEM images of $\mathrm{Sb}_{2} \mathrm{O}_{3}$ nanobelts self-assembled into 3-D flower-like nanostructures; (e), (f) high-magnification SEM images of the nanobelts incorporated in the 3-D nanostructures; (g), (h) high-magnification SEM images of the tips of the cross-sections of the nanobelts

sections is likely to give an ideal materials family for a systematic experimental and theoretical study of the fundamental electrical, optical, and thermal transport processes in 1-D nanostructures. It should be pointed out that most previously reported nanobelts have rectangular cross sections [1-4], and our report is the first demonstration that nanobelts can have elliptical cross sections. Thus, our results may cast new light on the investigation of property differences between nanobelts with rectangular cross sections and those with cross sections of other geometries.

The morphologies of the as-synthesized product were further investigated by TEM as shown in Figs. 4(a)-4(d), which also show that individual nanobelts and the 3-D flower-like nanostructures are built up of numerous individual $\mathrm{Sb}_{2} \mathrm{O}_{3}$ nanobelts, consistent 
with the SEM observations. The microstructure of an individual $\mathrm{Sb}_{2} \mathrm{O}_{3}$ nanobelt (see Fig. 4(e)) was further investigated in detail by HRTRM and SAED. A typical HRTEM image of a single $\mathrm{Sb}_{2} \mathrm{O}_{3}$ nanobelt is shown in Fig. 4(f). The central part of the nanobelt, shown in Fig. 4(i), gives lattice spacings of about 1.246 and $0.271 \mathrm{~nm}$, corresponding to the (010) and (002) planes of orthorhombic phase $\mathrm{Sb}_{2} \mathrm{O}_{3}$ (JCPDS Card No. 11-0689), respectively. In contrast, the edge part of the nanobelt (Fig. 4(j)) gives lattice spacings of about 0.312 and $0.271 \mathrm{~nm}$, corresponding to the (040) and (002) planes of orthorhombic phase (JCPDS Card No. 11-0689), respectively. The differences between the HRTEM images might be attributable to the surface of the single nanobelt not being flat, i.e., having a curve or arch-like morphology. The SAED pattern shown in the inset to Fig. $4(\mathrm{f})$ is a spot pattern, which reveals that the nanobelt is single crystalline in nature. The corresponding indexed fast Fourier transforms (FFTs) of the same areas show similar patterns to the SAED, indicating the formation of high quality singlecrystal orthorhombic $\mathrm{Sb}_{2} \mathrm{O}_{3}$ nanobelts. Both the HRTEM image and SAED pattern demonstrate that the nanobelts grow along the [001] direction (indicated with an arrow in Fig. 4(e)).

As shown in Fig. 5, the product shows peaks in the room temperature Raman spectrum at 142, 190, 219, 290, 439, 499, 595 , and $679 \mathrm{~cm}^{-1}$, which fit well with those reported by Cody et al. [36] (141, 189, $219,295,500,596$, and $690 \mathrm{~cm}^{-1}$ ) for the orthorhombic $\mathrm{Sb}_{2} \mathrm{O}_{3}$ phase. Orthorhombic $\mathrm{Sb}_{2} \mathrm{O}_{3}$ crystallizes in the space group Pccn $\left(\mathrm{D}_{2 \mathrm{~h}}{ }^{10}\right)$ and is built up of infinite polymeric $\mathrm{Sb}-\mathrm{O}-\mathrm{Sb}$ chains running along the $c$ axis with $\mathrm{Sb}-\mathrm{O}$ distances of $0.200 \mathrm{~nm}$. The Raman spectrum in the internal mode region (400-800 $\mathrm{cm}^{-1}$ ) of orthorhombic $\mathrm{Sb}_{2} \mathrm{O}_{3}$ is mainly dependent on the spectral features of the polymeric $\mathrm{Sb}-\mathrm{O}$ chains. The lattice mode region (below $400 \mathrm{~cm}^{-1}$ ), however, is controlled by the crystal space group and unit cell coupling [24, 37]. Thus, all signals below $400 \mathrm{~cm}^{-1}$ belong to the external lattice mode regime, while those above $400 \mathrm{~cm}^{-1}$ belong to the internal vibrations. In addition, we found that the Raman spectrum of the product calcined at $400^{\circ} \mathrm{C}$ for $3 \mathrm{~h}$ in air was almost identical to the uncalcined product, suggesting that the $\mathrm{Sb}_{2} \mathrm{O}_{3}$ nanobelts obtained from the solution at low temperature are wellcrystallized.

As shown in Fig. 6, the FT-IR spectra indicate

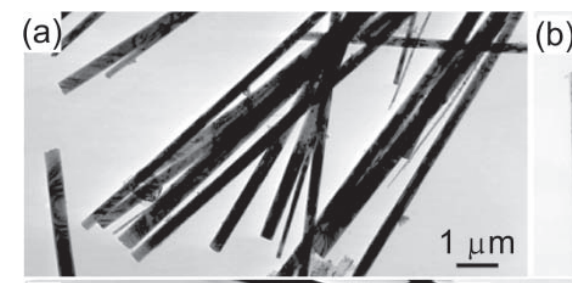

(c)
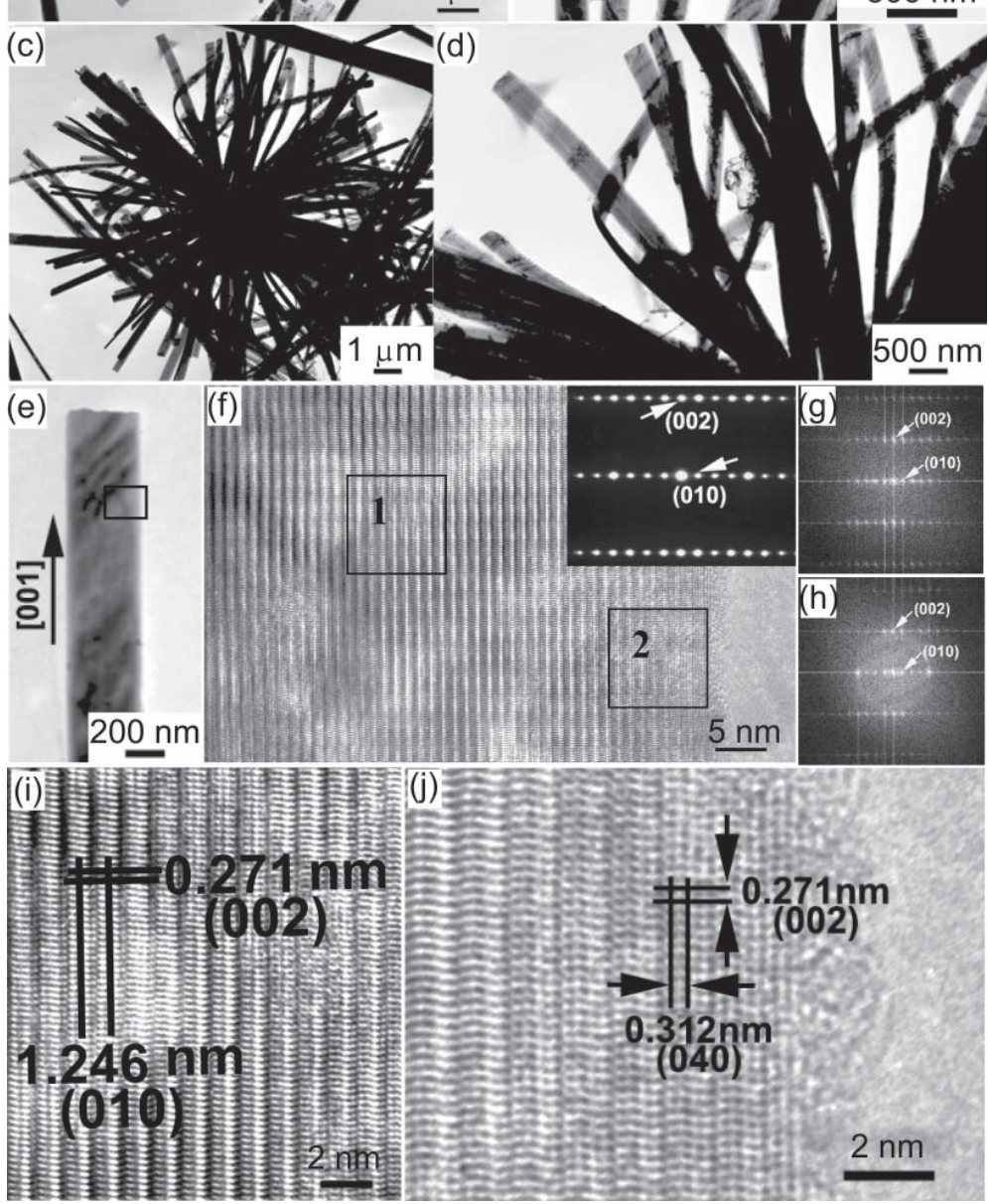

Figure 4 (a), (b) TEM images of $\mathrm{Sb}_{2} \mathrm{O}_{3}$ nanobelts; (c), (d) TEM images of the nanobelts self-assembled into 3-D flower-like nanostructures; (e) TEM image of an individual $\mathrm{Sb}_{2} \mathrm{O}_{3}$ nanobelt incorporated in the 3-D flower-like nanostructure; ( $\mathrm{f}$ ) HRTEM image of the part of the $\mathrm{Sb}_{2} \mathrm{O}_{3}$ nanobelt marked by a rectangle in (c) and (inset) the corresponding SAED pattern; (g), (i) indexed fast Fourier transforms (FFTs) and enlarged HRTEM image of the square area marked "1" in (f); (h), (j) indexed FFTs and enlarged HRTEM image of the square area marked " 2 " in ( $f$ )

\section{(1)}

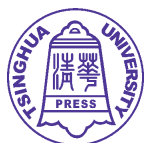




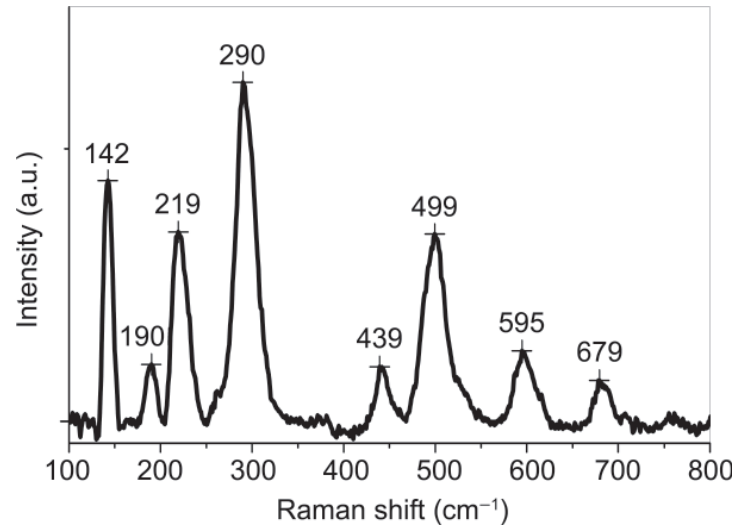

Figure 5 Room temperature Raman spectrum of the $\mathrm{Sb}_{2} \mathrm{O}_{3}$ nanobelts

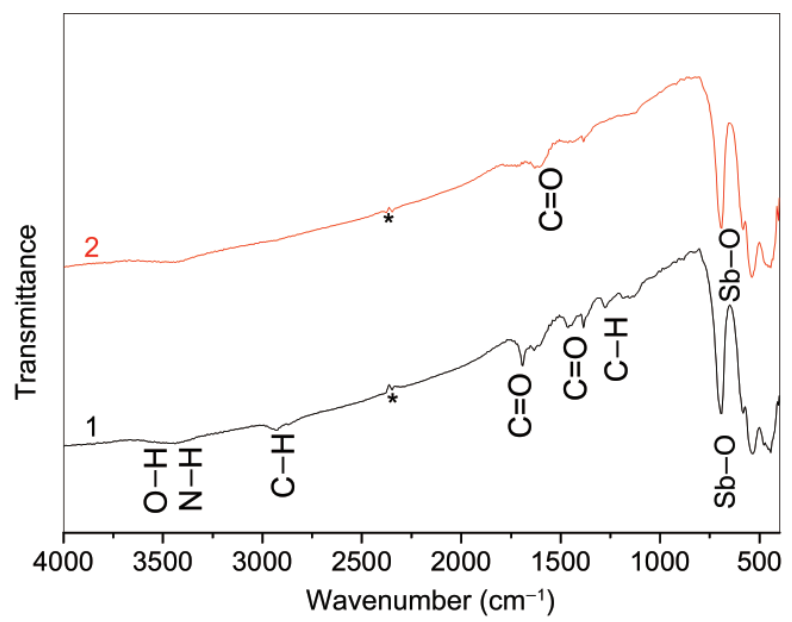

(a)

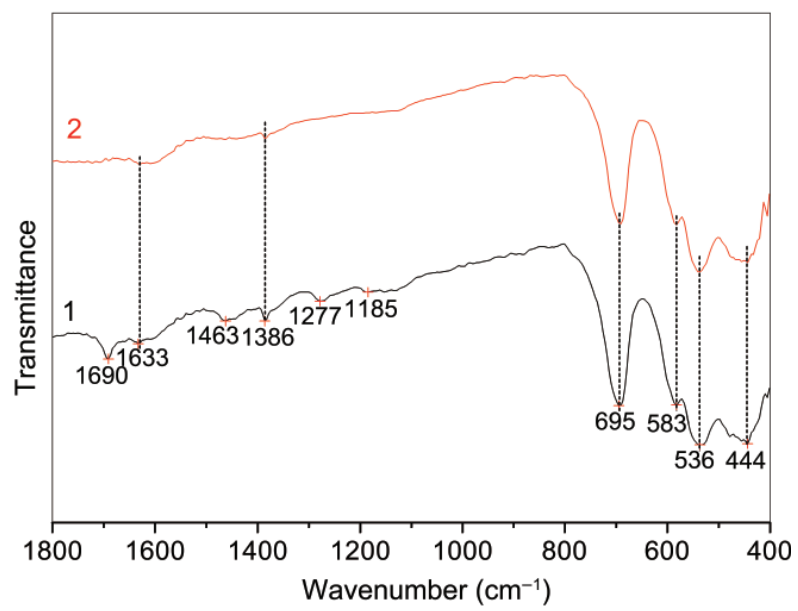

(b)

Figure 6 Room temperature FT-IR spectra of the $\mathrm{Sb}_{2} \mathrm{O}_{3}$ nanobelts (1) before and (2) after calcination: (a) in the range $4000-400 \mathrm{~cm}^{-1}$ and (b) in the range $1800-400 \mathrm{~cm}^{-1}$. Note the peaks marked by * come from $\mathrm{CO}_{2}$ in the environment that as-synthesized $\mathrm{Sb}_{2} \mathrm{O}_{3}$ nanobelt samples display very weak absorption peaks at 1185, 1277, 1463, and $2929 \mathrm{~cm}^{-1}$ which are associated with the characteristic $\mathrm{C}-\mathrm{H}$ vibrations coming from traces of ethylenediamine and polyvinylpyrolidone in the product. The peaks at 1386, 1633, and 1690 $\mathrm{cm}^{-1}$ are characteristic of $\mathrm{C}=\mathrm{O}$ stretching, and may arise from traces of polyvinylpyrrolidone. The peak at $3470 \mathrm{~cm}^{-1}$ is characteristic of $\mathrm{N}-$ $\mathrm{H}$ and $\mathrm{O}-\mathrm{H}$ stretching, consistent with traces of ethylenediamine or water being present. The low wavenumber region $400-800 \mathrm{~cm}^{-1}$ depicts the lattice vibrations of $\mathrm{Sb}_{2} \mathrm{O}_{3}$; peaks were observed at 444, 536,583 , and $695 \mathrm{~cm}^{-1}$ corresponding to symmetric and antisymmetric $\mathrm{Sb}-\mathrm{O}-\mathrm{Sb}$ vibrations $[24,36]$. The as-synthesized nanobelts could be further purified by calcination. After being calcined at $400{ }^{\circ} \mathrm{C}$ for 3 $\mathrm{h}$ in the air, most of the peaks attributed to traces of ethylenediamine, polyvinylpyrrolidone, and water were eliminated; however, the intensity of the $\mathrm{Sb}^{-}$ $\mathrm{O}-\mathrm{Sb}$ vibration peaks remained unchanged.

The growth mechanism of nanobelts with rectangular cross sections can be explained by the different growth rates of various crystal facets [1$4,24]$, but the growth mechanism of the nanobelts with elliptical cross sections is harder to understand. As the synthesis takes place in aqueous solution, the growth of $\mathrm{Sb}_{2} \mathrm{O}_{3}$ nanobelts with elliptical cross sections may be analyzed in terms of local thermodynamic equilibrium theory and concluded to be the result of the co-effects of the energy of surface tension and the energy of the crystal facets. Generally, the former tends to make the surface of the crystals round due to the associated reduction in surface area, while the latter tends to make it faceted due to the orthorhombic structure of $\mathrm{Sb}_{2} \mathrm{O}_{3}$. In addition, an "Ostwald ripening" effect may transform initially formed nanobelts with rectangular cross section into the final nanobelts with elliptical cross sections as the product was kept without disturbance for a period as long as $72 \mathrm{~h}$. The exact growth mechanism of the nanobelts with elliptical cross section is currently under investigation in our laboratory. The formation process of the 3-D flower-like nanostructures can be explained in terms of an organizing principle with an oriented attachment mechanism in which 
complex architectures can be built by the assembly route: $0-\mathrm{D} \rightarrow$ 1-D $\rightarrow$ 3-D [14-16]. Since metallic Sb particles are employed as the source, we assume that the preformed $\mathrm{Sb}_{2} \mathrm{O}_{3}$ oxide layer on the pristine $\mathrm{Sb}$ particles is crucial to the success of initial nucleation and the subsequent growth of 1-D nanostructures on the surface of the $\mathrm{Sb}$ particles. The experimental parameters such as temperature and amount of EA play an important role in the formation of $\mathrm{Sb}_{2} \mathrm{O}_{3}$ nanobelts with elliptical cross sections. Our previous study [24] showed that uniform, single-crystalline, well-faceted $\mathrm{Sb}_{2} \mathrm{O}_{3}$ nanowires with rectangular cross sections with lengths of hundreds of micrometers, typically $80-100 \mathrm{~nm}$ in width and 60-80 $\mathrm{nm}$ in thickness could be synthesized in a much shorter time of $5 \mathrm{~h}$ at room temperature. As shown in Fig. 7, the SEM images indicated that if the temperature was increased to $100{ }^{\circ} \mathrm{C}$, while keeping the other experimental parameters the same as for the synthesis of the $\mathrm{Sb}_{2} \mathrm{O}_{3}$ nanobelts, the resulting product is composed of micrometer-

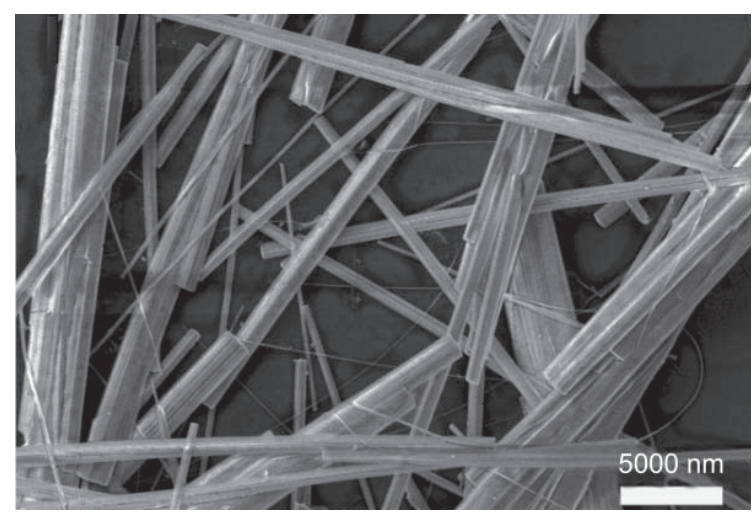

(a)

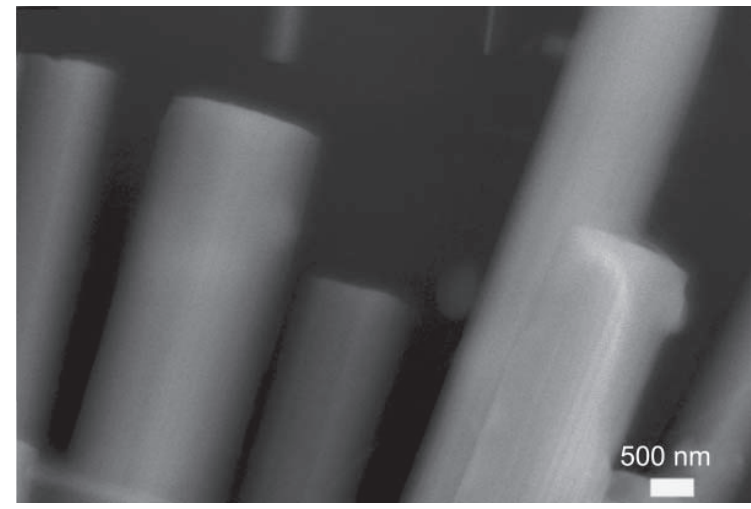

(b)

Figure $7 \mathrm{SEM}$ images of $\mathrm{Sb}_{2} \mathrm{O}_{3}$ micrometer-scale wires with rectangular cross section synthesized at $100{ }^{\circ} \mathrm{C}$ scale wires with rectangular cross-sections with lengths up to $50 \mu \mathrm{m}$ and average thickness around $2 \mu \mathrm{m}$. This growth process of $\mathrm{Sb}_{2} \mathrm{O}_{3} 3$-D flowerlike nanostructures is similar to the formation of $\mathrm{ZnO}$ nanoflowers from metallic $\mathrm{Zn}$ particles [38], which involves a surfactant-assisted solid-solutionsolid mechanism [39, 40]. In addition, similar nanobelts involving self-assembled nanostructures of cobalt phosphate have been synthesized by a hydrothermal reaction [41].

Figure 8(a) shows the excitation spectrum of $\mathrm{Sb}_{2} \mathrm{O}_{3}$ nanobelts with the emission monitored at $425 \mathrm{~nm}$. Three excitation peaks at $365 \mathrm{~nm}$ (strong peak), $348 \mathrm{~nm}$ (weak shoulder peak), and 380 $\mathrm{nm}$ (weak shoulder peak) can be observed in the excitation spectrum. As shown in Fig. 8(b), the photoluminescence spectrum of $\mathrm{Sb}_{2} \mathrm{O}_{3}$ nanobelts using an excitation wavelength of $365 \mathrm{~nm}$ shows an intense purple-blue emission at $425 \mathrm{~nm}(\sim 2.92 \mathrm{eV})$ with a full width at half maximum (FWHM) of 75 $\mathrm{nm}(0.47 \mathrm{eV})$. We have also examined the emission spectra of the nanostructures excited under different wavelengths $-325 \mathrm{~nm}, 348 \mathrm{~nm}, 375 \mathrm{~nm}, 390 \mathrm{~nm}$, and $395 \mathrm{~nm}$. It can be seen that the emission peak positions of the product remain almost unchanged under different excitation wavelengths, showing is an intrinsic property of the $\mathrm{Sb}_{2} \mathrm{O}_{3}$ nanobelts themselves. The photoluminescence spectra of the calcined $\mathrm{Sb}_{2} \mathrm{O}_{3}$ nanobelts samples were identical to those of the uncalcined samples as shown in Fig. 8(a). It is worth noting that room temperature ultraviolet (UV) bandedge photoluminescence with a peak at $374 \mathrm{~nm}$ has previously been observed for $\mathrm{Sb}_{2} \mathrm{O}_{3}$ nanowires [24]. The purple-blue photoluminescence at $425 \mathrm{~nm}(\sim 2.92$ $\mathrm{eV}$ ) is probably due to a triplet to ground transition of a neutral oxygen vacancy defect, as suggested by $a b$ initio molecular orbital calculations for many other well-studied metal oxides such as $\mathrm{ZnO}$ and $\mathrm{SnO}_{2}[42$, 43]. Considering that the energy gap of bulk $\mathrm{Sb}_{2} \mathrm{O}_{3}$ is $3.3 \mathrm{eV}$, the purple-blue luminescence from $\mathrm{Sb}_{2} \mathrm{O}_{3}$ nanobelts can be attributed to oxygen-related defects that have been introduced during growth. The interactions between oxygen vacancies and interfacial antimony vacancies would lead to the formation of a significant number of trapped states, which form a series of metastable energy levels within the band 


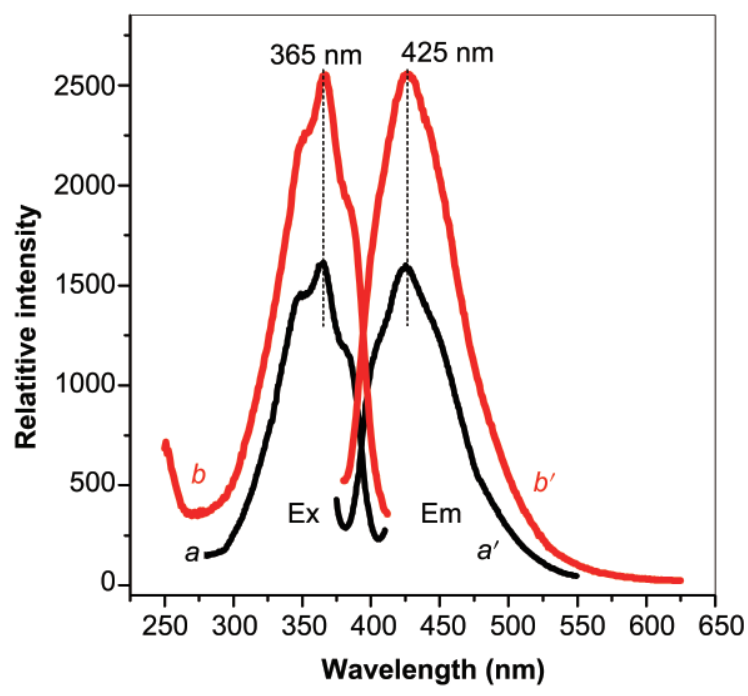

(a)

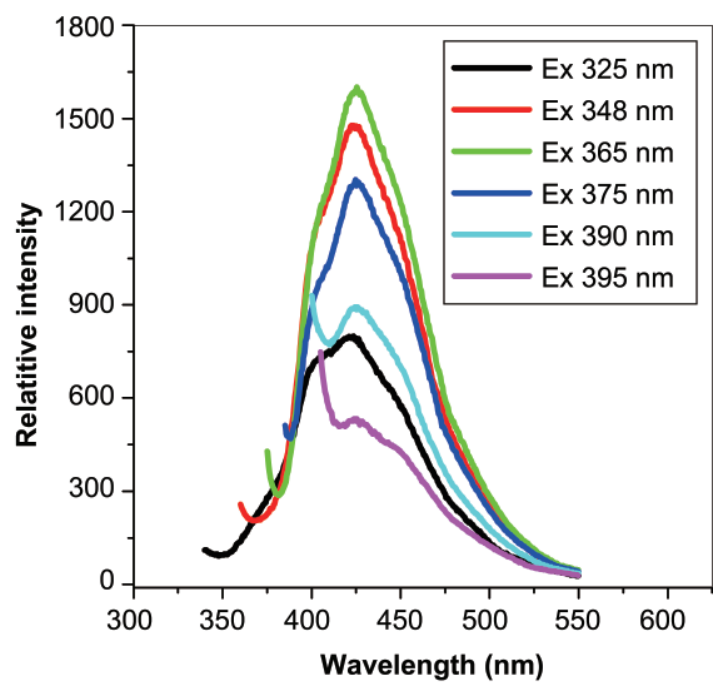

(b)

Figure 8 (a) Room temperature photoluminescence ( $\mathrm{PL}$ ) spectra of $\mathrm{Sb}_{2} \mathrm{O}_{3}$ nanobelts before (lines $a$ and $a^{\prime}$ ) and after calcination (lines $b$ and $b^{\prime}$ ). The spectra indicate that the PL excitation peaks (lines $a$ and $b$ ) are at $365 \mathrm{~nm}$, while the PL emission peaks (lines $a^{\prime}$ and $b^{\prime}$ ) are at $425 \mathrm{~nm}$. (b) The photoluminescence emission spectra with various excitation wavelengths of $\mathrm{Sb}_{2} \mathrm{O}_{3}$ nanobelts before calcination

gap, and result in a strong photoluminescence signal at room temperature. Actually, there is a lack of investigation of luminescence in $\mathrm{Sb}_{2} \mathrm{O}_{3}$ systems so that the origin and the mechanism of the emission require further investigation, such as fluorescence lifetime measurements.

\section{Conclusions}

In summary, we have demonstrated that orthorhombic $\mathrm{Sb}_{2} \mathrm{O}_{3}$ nanobelts with unique elliptical cross sections and 3-D flower-like nanostructures built up from tens of nanobelts can be obtained from aqueous solution. Optical measurements reveal that the $\mathrm{Sb}_{2} \mathrm{O}_{3}$ nanobelts display intense purpleblue photoluminescence centered at $425 \mathrm{~nm}$. We envisage that the as-obtained $\mathrm{Sb}_{2} \mathrm{O}_{3}$ nanobelts may be a potential new candidate for effective purpleblue light emitters, and might also be valuable for future theoretical research and nanodevice design. In addition, the present study may cast new light on the investigation of property differences between nanobelts with rectangular cross sections and elliptical cross sections. By suitable choice of source materials and synthesis parameters, it is reasonable to expect that the present study could be extended to the synthesis of other novel metal oxide nanobelts and the corresponding 3-D nanostructures.

\section{Acknowledgements}

We are grateful to Fee Li Lie at the University of Arizona for help with the XPS characterization and for financial support from the National Natural Science Foundation of China (Nos. 60736001, 60572031, and 20571080) and Science Foundation Arizona (Strategic Research Group Program).

Electronic Supplementary Material: Additional SEM and TEM images of $\mathrm{Sb}_{2} \mathrm{O}_{3}$ nanobelts with elliptical cross-section are available in the online version of this article at http://dx.doi.org/10.1007/s12274-0099014-y and are accessible free of charge.

\section{References}

[1] Pan, Z. W.; Dai, Z. R.; Wang, Z. L. Nanobelts of semiconducting oxides. Science 2001, 291, 1947-1949.

[2] Shi, W.; Peng, H.; Wang, N.; Li, C. P.; Xu, L.; Lee, C. S.; Kalish, R.; Lee, S. T. Free-standing single crystal silicon nanoribbons. J. Am. Chem. Soc. 2001, 123, 1109511096.

[3] Yu, Y.; Wang, R. H.; Chen, Q.; Peng, L. M. High-quality ultralong $\mathrm{Sb}_{2} \mathrm{~S}_{3}$ nanoribbons on large scale. J. Phys. 
Chem. B 2005, 109, 23312-23315.

[4] Hu, C. G.; Liu, H.; Dong, W. T.; Zhang, Y. Y.; Bao, G.; Lao, C. S.; Wang, Z. L. $\mathrm{La}(\mathrm{OH})_{3}$ and $\mathrm{La}_{2} \mathrm{O}_{3}$ nanobeltsSynthesis and physical properties. Adv. Mater. 2007, 19, 470-474.

[5] Arnold, M. S.; Avouris, P.; Wang, Z. L. Field-effect transistors based on single semiconducting oxide nanobelts. J. Phys. Chem. B 2003, 107, 659-663.

[6] Comini, E.; Faglia, G.; Sberveglieri, G.; Pan, Z. W.; Wang, Z. L. Stable and highly sensitive gas sensors based on semiconducting oxide nanobelts. Appl. Phys. Lett. 2002, 81, 1869-1871.

[7] Bai, X. D.; Gao, P. X.; Wang, Z. L.; Wang, E. G. Dualmode mechanical resonance of individual $\mathrm{ZnO}$ nanobelts. Appl. Phys. Lett. 2003, 82, 4806-4808.

[8] Hughes, W.; Wang, Z. L. Nanobelts as nanocantilevers. Appl. Phys. Lett. 2003, 82, 2886-2888.

[9] Yan, H.; Johnson, J.; Law, M.; He, R.; Knutsen, K.; McKinney, J. R.; Pham, J.; Saykally, R.; Yang, P. ZnO nanoribbon microcavity lasers. Adv. Mater. 2003, 15 1907-1911.

[10] Xiong, Q. H.; Wang, J. G.; Reese, O.; Voon, L. C. L. Y.; Eklund, P. C. Raman scattering from surface phonons in rectangular cross-sectional w-ZnS nanowires. Nano Lett. 2004, 4, 1991-1996.

[11] Xia, Y. N.; Yang, P. D.; Sun, Y. G.; Wu, Y. Y.; Mayers, B.; Gates, B.; Yin, Y. D.; Kim, F.; Yan, Y. Q. Chemistry and physics of nanowires. Adv. Mater. 2003, 15, 353-389.

[12] Gao, P.; Wang, Z. L. Self-Assembled nanowirenanoribbon junction arrays of $\mathrm{ZnO}$. J. Phys. Chem. $B$ 2002, 106, 12653-12658.

[13] Lao, J. Y.; Wen, G. J.; Ren, Z. F. Hierarchical ZnO nanostructures. Nano Lett. 2002, 2, 1287-1291.

[14] Liu, B.; Zeng, H. C. Fabrication of ZnO "dandelions" via a modified Kirkendall process. J. Am. Chem. Soc. 2004, 126, 16744-16746.

[15] Li, Z. Q.; Ding, Y.; Xiong, Y. J.; Yang, Q.; Xie, Y. One-step solution-based catalytic route to fabricate novel $\alpha-\mathrm{MnO}_{2}$ hierarchical structures on a large scale. Chem. Commun. 2005, 918-920.

[16] Yao, W. T.; Yu, S. H.; Liu, S. J.; Chen, J. P.; Liu, X. M.; Li, F. Q. Architectural control syntheses of CdS and CdSe nanoflowers, branched nanowires, and nanotrees via a solvothermal approach in a mixed solution and their photocatalytic property. J. Phys. Chem. B 2006, 110, 11704-11710.
[17] Guo, L.; Wu, Z. H.; Liu, T.; Wang, W. D.; Zhu, H. S. Synthesis of novel $\mathrm{Sb}_{2} \mathrm{O}_{3}$ and $\mathrm{Sb}_{2} \mathrm{O}_{5}$ nanorods. Chem. Phys. Lett. 2000, 318, 49-52.

[18] Friedrichs, S.; Meyer, R. R.; Sloan, J.; Kirkland, A. I.; Hutchison, J. L.; Green, M. L. H. Complete characterisation of a $\mathrm{Sb}_{2} \mathrm{O}_{3} /(21,-8)$ SWNT inclusion composite. Chem. Commun. 2001, 929-930.

[19] Ye, C. H.; Meng, G. W.; Zhang, L. D.; Wang, G. Z.; Wang, Y. H. A facile vapor-solid synthetic route to $\mathrm{Sb}_{2} \mathrm{O}_{3}$ fibrils and tubules. Chem. Phys. Lett. 2002, 363, 34-38.

[20] Zhang, Y. X.; Li, G. H.; Zhang, J.; Zhang, L. D. Shape-controlled growth of one-dimensional $\mathrm{Sb}_{2} \mathrm{O}_{3}$ nanomaterials. Nanotechnology 2004, 15, 762-765.

[21] Chen, X. Y.; Wang, X.; An, C. H.; Liu, J. W.; Qian, Y. $\mathrm{T}$. Synthesis of $\mathrm{Sb}_{2} \mathrm{O}_{3}$ nanorods under hydrothermal conditions. Mater. Res. Bull. 2005, 40, 469-474.

[22] Christian, P.; O'Brien, P. The preparation of antimony chalcogenide and oxide nanomaterials. J. Mater. Chem. 2005, 15, 4949-4954.

[23] Sendor, D.; Weirich, T.; Simon, U. Transformation of nanoporous oxoselenoantimonates into $\mathrm{Sb}_{2} \mathrm{O}_{3}$ nanoribbons and nanorods. Chem. Commum. 2005, 5790-5792.

[24] Deng, Z. T.; Tang F. Q.; Chen D.; Meng X. W.; Cao, L.; Zou. B. S. A simple solution route to single-crystalline $\mathrm{Sb}_{2} \mathrm{O}_{3}$ nanowires with rectangular cross sections. J. Phys. Chem. B 2006, 110, 18225-18230.

[25] Chand, N.; Verma, S. Surface and strength properties of $\mathrm{PVC}-\mathrm{Sb}_{2} \mathrm{O}_{3}$ flame retardant coated sunhemp fiber. J. Fire Sci. 1991, 9, 251-258.

[26] Sato, H.; Kondo, K.; Tsuge, S.; Ohtani, H.; Sato, N. Mechanisms of thermal degradation of a polyester flameretarded with antimony oxide/brominated polycarbonate studied by temperature-programmed analytical pyrolysis. Polym. Degrad. Stab. 1998, 62, 41-48.

[27] Liu, H. H.; Iwasawa, Y. Unique performance and characterization of a crystalline $\mathrm{SbRe}_{2} \mathrm{O}_{6}$ catalyst for selective ammoxidation of isobutane. J. Phys. Chem. $B$ 2002, 106, 2319-2329.

[28] Ha, Y.; Wang, M. Capillary melt method for micro antimony oxide $\mathrm{pH}$ electrode. Electroanalysis 2006, 18, 1121-1125.

[29] Deng, Z. T.; Chen, D.; Tang, F. Q.; Meng, X. W.; Ren, J.; Zhang, L. Orientated attachment assisted self-assembly of $\mathrm{Sb}_{2} \mathrm{O}_{3}$ nanorods and nanowires: End-to-end versus side-by-side. J. Phys. Chem. C. 2007, 111, 5325-5330. 
[30] Deng, Z. T.; Peng, B.; Chen, D.; Tang, F. Q.; Muscat, A. J. A new route to self-assembled tin dioxide nanospheres: Fabrication and characterization. Langmuir; 2008, 24, 11089-11095.

[31] Deng, Z. T.; Chen, D.; Peng, B.; Tang, F. Q. From bulk metal $\mathrm{Bi}$ to two-dimensional well-crystallized BiOX $(\mathrm{X}=\mathrm{Cl}, \mathrm{Br})$ micro- and nanostructures: Synthesis and characterization. Cryst. Growth Des. 2008, 8, 29953003.

[32] Deng, Z. T.; Tang, F. Q.; Muscat, A. J. Strong blue photoluminescence from single-crystalline bismuth oxychloride nanoplates. Nanotechnology 2008, 19, 295705.

[33] Wagner, C. D. Sensitivity factors for XPS analysis of surface atoms. J. Electron Spectrosc. Relat. Phenom. 1983, 32, 99-102.

[34] Moulder, J.; Stickie, W.; Sobal, P.; Bomber, K. Handbook of $X$-ray Photoelectron Spectroscopy; Perkin Elmer: Eden Prairie, MN, 1992.

[35] Liu, K. S.; Zhai, J.; Jiang, L. Fabrication and characterization of superhydrophobic $\mathrm{Sb}_{2} \mathrm{O}_{3}$ films. Nanotechnology, 2008, 19, 165604.

[36] Cody, C. A.; DiCarlo, L.; Darlington, R. K. Vibrational and thermal study of antimony oxides. Inorg. Chem. 1979, $18,1572-1576$.
[37] Mestl, G.; Ruiz, P.; Delmon, B.; Knozinger, H. Sb $\mathrm{O}_{3} / \mathrm{Sb}_{2} \mathrm{O}_{4}$ in reducing/oxidizing environments: $A n$ in situ Raman spectroscopy study. J. Phys. Chem. 1994, 11276-11282.

[38] Liu, B.; Zeng, H. C. Hydrothermal synthesis of $\mathrm{ZnO}$ nanorods in the diameter regime of $50 \mathrm{~nm}$. J. Am. Chem. Soc. 2003, 125, 4430-4431.

[39] Mayers, B.; Gates, B.; Yin, Y. D.; Xia, Y. N. Large-scale synthesis of monodispersed nanorods of Se/Te alloys through a homogeneous nucleation and solution growth process. Adv. Mater. 2001, 13, 1380-1384.

[40] Liu, Z. P.; Peng, S.; Xie, Q.; Hu, Z. K.; Yang, Y.; Zhang, S. Y.; Qian, Y. T. Large-scale synthesis of ultralong $\mathrm{Bi}_{2} \mathrm{~S}_{3}$ nanoribbons via a solvothermal process. Adv. Mater. 2003, 15, 936-940.

[41] Che, R, C.; Peng, L. M.; Zhou, W. Z. Synthesis and characterization of crystalline microporous cobalt phosphite nanowires. Appl. Phys. Lett. 2005, 87, 173122.

[42] Hsu, J. W. P.; Tallant, D. R.; Simpson, R. L.; Missert, N. A.; Copel, R. G. Luminescent properties of solution-grown ZnO nanorods. Appl. Phys. Lett. 2006, 88, 252103.

[43] Her, Y. C.; Wu, J. Y.; Lin, Y. R.; Tsai, S. Y. Lowtemperature growth and blue luminescence of $\mathrm{SnO}_{2}$ nanoblades. Appl. Phys. Lett. 2006, 89, 043115. 